\title{
Hypoxemic reperfusion of ischemic states: an alternative approach for the attenuation of oxidative stress mediated reperfusion injury
}

\author{
Marios-Konstantinos Tasoulis ${ }^{1 *}$ and Emmanuel E. Douzinas ${ }^{2}$
}

\begin{abstract}
Ischemia and reperfusion (I/R) - induced injury has been described as one of the main factors that contribute to the observed morbidity and mortality in a variety of clinical entities, including myocardial infarction, ischemic stroke, cardiac arrest and trauma. An imbalance between oxygen demand and supply, within the organ beds during ischemia, results in profound tissue hypoxia. The subsequent abrupt oxygen re-entry upon reperfusion, may lead to a burst of oxidative aggression through production of reactive oxygen species by the primed cells. The predominant role of oxidative stress in the pathophysiology of I/R mediated injury, has been well established. A number of strategies that target the attenuation of the oxidative burst have been tested both in the experimental and the clinical setting. Despite these advances, $1 / R$ injury continues to be a major problem in everyday medical practice. The aim of this paper is to review the existing literature regarding an alternative approach, termed hypoxemic reperfusion, that has exhibited promising results in the attenuation of I/R injury, both in the experimental and the clinical setting. Further research to clarify its underlying mechanisms and to assess its efficacy in the clinical setting is warranted.
\end{abstract}

Keywords: Reperfusion injury, Hypoxemic reperfusion, Oxidative stress, Reactive oxygen species

\section{Background}

Tissue hypoxia due to ischemia is the common denominator in a variety of clinical emergencies of either regional distribution such as myocardial infarction and mesenteric embolism, or of systemic involvement such as cardiac arrest and hemorrhagic shock, both of which represent the equivalent of whole body ischemia.

The aforementioned conditions are sometimes fatal because of the injury that lurks to appear, the so called ischemia - reperfusion (I/R) injury. This represents somehow, the cost of optimal reperfusion or effective resuscitation from longstanding insults of ischemia. Reperfusion injury does not occur during the preceding ischemic period; rather, this injury refers to a causal event associated with reperfusion. This event may result in a number

\footnotetext{
* Correspondence: mtasoulis@med.uoa.gr

${ }^{1}$ 2nd Department of Surgery, National and Kapodistrian University of Athens, Medical School, Aretaieion University Hospital, 76 Vas. Sofias Ave, 11528 Athens, Greece

Full list of author information is available at the end of the article
}

of detrimental effects including multiple organ failure (MOF) and death. Over the last several decades, a variety of treatment modalities have been evaluated to attenuate $\mathrm{I} / \mathrm{R}$ injury. Hypoxemic reperfusion, in particular, may be particularly promising. The aim of this review is to summarize the existing literature regarding the underlying mechanisms and potential applications of hypoxemic reperfusion in a variety of clinical scenarios of regional and systemic I/R injury.

\section{Review}

Strategies of reperfusion injury prevention

Reactive oxygen species have been found to play a key role in the pathophysiology of $I / R$ injury [1]. Oxidative stress generated during reperfusion, may mediate injury to the insulted tissues. This phenomenon is part of the term "oxygen paradox», in which reoxygenation of an ischemic tissue produces a degree of injury that greatly exceeds the injury induced by ischemia alone [2]. However, oxidative stress, contributes to I/R injury - induced 
damage in a consecutive two - phase pattern. In addition to its direct cytotoxic effects, the burst of free radicals, generated by oxidative stress, also induces the formation of inflammatory mediators [3] through redoxmediated signalling pathways, leading to post ischemia reperfusion inflammatory injury $[2,3]$. These oxidative and inflammatory responses have been implicated in the development of MOF, a detrimental manifestation often following $I / R$.

The above knowledge has led medical research to focus on the development of potential strategies aimed at eliminating the effects of reactive oxygen species (ROS) and of the systemic inflammatory response during reperfusion. Suggested methods include:

- use of antioxidants in order to minimize the oxidative stress [4-7]

- scavengers for the removal of metabolic waste

- preconditioning techniques (ischemic, hypoxic, pharmacologic and remote ischemic preconditioning) to prepare cells to better respond to the forthcoming stress [8-17]

Despite the proven beneficial effects, all the above strategies share one common disadvantage: they lack effectiveness when they are applied after or during reperfusion/resuscitation. This limits their usefulness in the clinical setting. Antioxidants should be administered ideally before ischemia and reperfusion in order to achieve their maximum effect. In fact, most available evidence regarding their favorable effects derives from studies in which antioxidants were used as pre-treatment $[5,7]$. Moreover, their use, even in combination with scavengers, does not completely abolish the ensuing injury. The same applies for the use of preconditioning techniques. The rationale of these techniques is to pre-medicate the patient, which may not be feasible in all clinical scenarios. Therefore, the application of these strategies in the clinical setting may be limited [14-16, 18, 19]. A recent metaanalysis questioned the efficacy of ischemic preconditioning in the setting of liver surgery [20]. Similarly, remote ischemic preconditioning, a technique that held great promise for its demonstrated favorable effects, did not exert the expected outcomes when tested in clinical trials [21-23].

Despite the controversial results in the clinical setting, the existing literature regarding these strategies provides additional evidence, confirming the oxidative nature of the injury following reperfusion. The pivotal role of oxidative stress mediated reperfusion injury has been well established. Using a rabbit experimental model, it was shown that resuscitation from hemorrhagic shock resulted in acute lung injury with enhanced oxidative and inflammatory pulmonary responses. However, the degree of injury correlated only with the extent of oxidative aggression [24].

\section{Hypoxemic reperfusion}

Given that the abundance of oxygen supply, initially during reperfusion, produces a burst of ROS generation, the important question was whether this phenomenon could be attenuated by manipulating the oxygen content in the initial blood perfusate in order to meet with the adapted -at low cellular energy level- needs during ischemia.

Over the last years, a growing body of literature examines the effect of ischemic post-conditioning, which seems to be a promising approach [25-30]. This method is based on the concept that gradual reperfusion of a previously ischemic tissue, interrupted with short-lived episodes of ischemia, might yield favorable results. A closely related technique, termed "remote ischemic postconditioning", involves initiation of transient episodes of ischemia in a remote tissue or organ at the time of reperfusion [31-34]. A third, relatively new approach, similar to these is hypoxic post-conditioning, characterized by reperfusion under normoxia alternated with periods of hypoxia [35-38].

This is where hypoxemic reperfusion appears. It is about gradually increasing the $\mathrm{FiO}_{2}$ of the reperfusate from a lower level in order to maintain $\mathrm{P}_{\mathrm{a}} \mathrm{O}_{2}$ levels of $30-35 \mathrm{mmHg}$, initially during reperfusion, to gradually achieve $\mathrm{P}_{\mathrm{a}} \mathrm{O}_{2}$ levels of $95-105 \mathrm{mmHg}$ at the end of the resuscitation period. Historically, the accepted dogma was to give as much oxygen as possible to treat ischemic states. However, to deliver oxygen in plenty, particularly early in reperfusion, may only lead to higher quantities of ROS. Therefore, the imperative is to supply sufficient oxygen to meet tissue oxygen demand to maintain vital functions while minimizing reperfusion injury related to an abundance of ROS. Experimental findings indicate a significant correlation between $\mathrm{P}_{\mathrm{a}} \mathrm{O}_{2}$ and the phosphocreatine/inorganic phosphate ratio or intracellular $\mathrm{pH}$. However, for $\mathrm{P}_{\mathrm{a}} \mathrm{O}_{2}$ ranging from 130 to $33 \mathrm{mmHg}$, metabolite changes were not significant. Both the ratio as well as the intracellular $\mathrm{pH}$ decreased significantly when $\mathrm{P}_{\mathrm{a}} \mathrm{O}_{2}$ was lowered below 33 and $28 \mathrm{mmHg}$ respectively [39]. Moreover, the seemingly paradoxical idea of hypoxemic reperfusion is very similar to the aforementioned strategies of post-conditioning in terms of physiology. What is common in these two methods is the lower delivery of oxygen early during reperfusion so as not to provide it in abundance to form ROS. How is this possible? Delivery of oxygen is calculated by the following formula: $\mathrm{DO}_{2}=\mathrm{CO} \times \mathrm{C}_{\mathrm{a}} \mathrm{O}_{2}\left(\mathrm{C}_{\mathrm{a}} \mathrm{O}_{2}=13.4 \times[\mathrm{Hb}] \times \mathrm{S}_{\mathrm{a}} \mathrm{O}_{2}+\right.$ $\left.0.03 \mathrm{P}_{\mathrm{a}} \mathrm{O}_{2}\right)$. During post-conditioning the altered parameter is the cardiac output $(\mathrm{CO})$ through the gradual reperfusion whereas during hypoxemic reperfusion the altered parameter is $\mathrm{S}_{\mathrm{a}} \mathrm{O}_{2}$ and $\mathrm{P}_{\mathrm{a}} \mathrm{O}_{2}$ through the gradual increase of $\mathrm{FiO}_{2}$.

The basic underlying concept of hypoxemic reperfusion is that when reperfusion of a previously ischemic 
tissue takes place under hypoxemia, the cells will not be supplied with an abundance of oxygen, which will be available for ROS production (Fig. 1a). Alternatively, it is hypothesized that the gradual reintroduction of oxygen in increasing concentration during reperfusion, corresponding to the increasing tissue requirements, may be used by the mitochondria for the generation of ATP and the restoration of the cell's energy resources (Fig. 1b). Therefore, hypoxemic reperfusion represents a strategy that can be applied after the occurrence of the ischemic insult, at the beginning of reperfusion. This could be a significant advantage when compared to other reperfusion strategies, including the use of antioxidants and preconditioning, since these techniques need to be implemented before reperfusion to show their beneficial effects $[5,7,14-16]$. Another potential advantage of hypoxemic reperfusion compared to the use of antioxidants, is that it aims to prevent ROS production rather than eliminate their deleterious effects. Moreover,

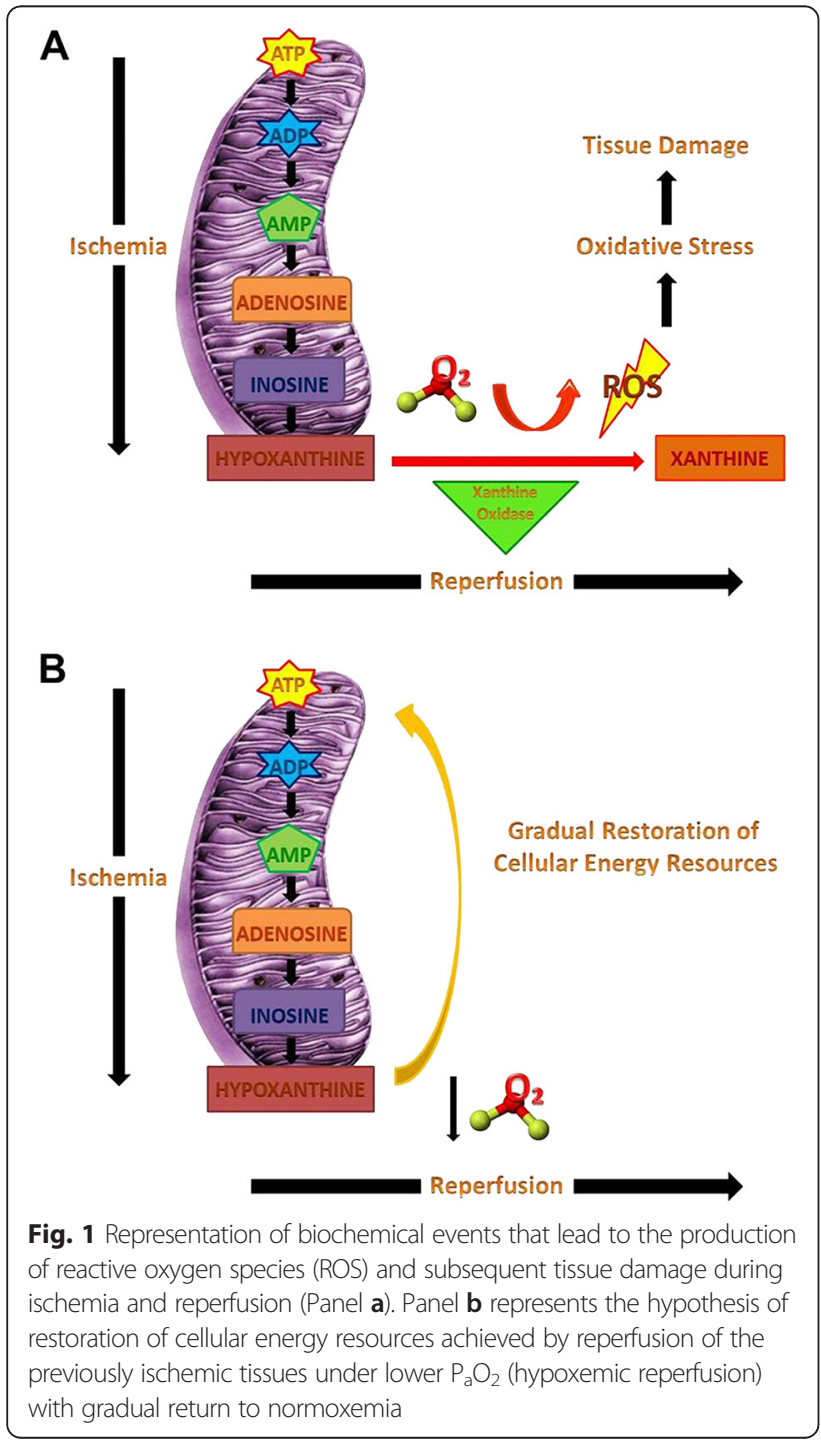

hypoxemic reperfusion may be advantageous compared to post-conditioning strategies since blood flow is restored offering better replenishment from metabolic wastes. However, apart from the theory, the method should be examined in vivo. Indeed the existing evidence, summarized in Table 1, exhibit remarkably favorable results in various applications both in the experimental and the clinical setting.

\section{Gastrointestinal tract reperfusion injury}

Ischemia - reperfusion induced injury of the gastrointestinal tract can ensue from a variety of clinical conditions such as mesentery artery embolism. In 1988, Perry et al. showed, for the first time, that gradual reintroduction of oxygen reduced reperfusion injury as evidenced by decreased gastric mucosal bleeding after ischemia in a cat experimental model [40].

A subsequent set of experiments, further demonstrated the favorable effect of hypoxemic reperfusion in the setting of I/R injury of the gastrointestinal tract. Specifically, using a porcine model of intestinal ischemia, through clamping of the superior mesenteric artery [41, 42], it was shown that hypoxemic reperfusion resulted in decreased gut barrier dysfunction as evidenced by the lower incidence of positive Limulus test [41]. Both the oxidative and the inflammatory responses were also attenuated as demonstrated by the decrease in intestinal mucosa malondialdehyde (MDA) [42] and portal blood interleukin (IL) -1b levels [41]. The application of this method resulted in a decrease of the observed histopathologic injury not only of the intestine [41] but also of remote organs such as the heart [42] and lung [41]. This finding implies a systemic favorable effect and highlights the potential role of hypoxemic reperfusion in the prevention of MOF through attenuation of oxidative and inflammatory responses. Furthermore, animals that underwent hypoxemic reperfusion had a superior hemodynamic profile as evidenced by mean arterial pressure preservation, lower need for inotropic support, and a trend towards $\mathrm{S} \quad \mathrm{O}_{2}$ restoration [42].

\section{Brain reperfusion injury}

The brain is thought to be the most vulnerable organ in hypoxic challenges. Compromise of cerebral perfusion and thus oxygen delivery may follow cardiac arrest, traumatic brain injury, ischemic stroke etc. In these cases, the restoration of blood flow may lead to reperfusion injury. The efficacy of gradual reintroduction of oxygen in the previously ischemic brain has been tested in a dog experimental model by Burda et al [43]. They used a global brain ischemia model produced by cross-clamping of the left subclavian artery and the brachiocephalic trunk at the point of their emergence from the aorta and showed that the animals that underwent reperfusion under hypoxemia 
Table 1 Summary of hypoxemic reperfusion studies

\begin{tabular}{|c|c|c|c|c|}
\hline Study & Type of study & Model of ischemia & Reperfusion protocol & Outcome \\
\hline Perry et al. [40] & Experimental & $\begin{array}{l}\text { Celiac artery ischemia through } \\
\text { adjustable screw clamp }\end{array}$ & $\begin{array}{l}\mathrm{Pa}_{\mathrm{a}} \mathrm{O}_{2}=34 \mathrm{mmHg} \text { for } 1 \mathrm{~h} \text { before } \\
\text { return to normal perfusion }\end{array}$ & $\downarrow$ gastric mucosal bleeding \\
\hline \multirow[t]{2}{*}{ Douzinas et al. [41] } & \multirow[t]{2}{*}{ Experimental } & \multirow[t]{2}{*}{ SMA clamping } & \multirow{2}{*}{$\begin{array}{l}\mathrm{PaO}_{2}=30-35 \mathrm{mmHg} \text { with gradual } \\
\text { return to normoxemia over a } 2 \mathrm{~h} \\
\text { period }\end{array}$} & $\begin{array}{l}\text { \intestinal mucosa and } \\
\text { lung injury }\end{array}$ \\
\hline & & & & $\downarrow$ inflammatory response \\
\hline \multirow[t]{3}{*}{ Douzinas et al. [42] } & \multirow[t]{3}{*}{ Experimental } & \multirow[t]{3}{*}{ SMA clamping } & \multirow{3}{*}{$\begin{array}{l}\mathrm{P}_{\mathrm{a}} \mathrm{O}_{2}=30-35 \mathrm{mmHg} \text { with gradual } \\
\text { return to normoxemia over a } 2 \mathrm{~h} \\
\text { period }\end{array}$} & $\uparrow$ hemodynamic profile \\
\hline & & & & $\downarrow$ oxidative response \\
\hline & & & & $\downarrow$ myocardial injury \\
\hline Burda et al. [43] & Experimental & $\begin{array}{l}\text { Clamping of left subclavian artery } \\
\text { and brachiocephalic trunk }\end{array}$ & $\begin{array}{l}\mathrm{P}_{\mathrm{a}} \mathrm{O}_{2}=37.5 \mathrm{mmHg} \text { with gradual } \\
\text { return to normoxemia over a } \\
15-30 \text { minute period }\end{array}$ & $\uparrow c e r e b r a l$ protein synthesis \\
\hline \multirow[t]{2}{*}{ Douzinas et al. [44] } & \multirow[t]{2}{*}{ Experimental } & \multirow{2}{*}{$\begin{array}{l}\text { Global cerebral ischemic insult through } \\
\text { decrease of MAP, bilateral clamping } \\
\text { of carotid arteries and cessation } \\
\text { of respiration }\end{array}$} & \multirow{2}{*}{$\begin{array}{l}\mathrm{FiO}_{2}=0.12 \text { with gradual increase to } \\
\text { achieve } \mathrm{P}_{\mathrm{a}} \mathrm{O}_{2}=100 \mathrm{mmHg} \text { over a } 1 \mathrm{~h} \\
\text { period }\end{array}$} & $\uparrow$ neurological outcome \\
\hline & & & & $\downarrow$ oxidative response \\
\hline Douzinas et al. [45] & Experimental & $\begin{array}{l}\text { Global cerebral ischemic insult through } \\
\text { decrease of MAP, bilateral clamping of } \\
\text { carotid arteries and cessation of respiration }\end{array}$ & $\begin{array}{l}\mathrm{PaO}_{2} \mathrm{O}_{2}=30-35 \mathrm{mmHg} \text { with gradual } \\
\text { increase to achieve } \mathrm{P}_{\mathrm{a}} \mathrm{O}_{2}=100 \mathrm{mmHg} \\
\text { over a } 1 \mathrm{~h} \text { period }\end{array}$ & $\downarrow$ cerebral injury \\
\hline Hickey et al. [46] & Experimental & Deep hypothermic circulatory arrest & $\begin{array}{l}\mathrm{Pa}_{\mathrm{a}} \mathrm{O}_{2}=40-50 \mathrm{mmHg} \text { throughout the } \\
\text { reperfusion period }\end{array}$ & 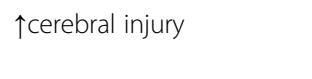 \\
\hline \multirow[t]{3}{*}{ Abdel-Rahman et al. [47] } & \multirow[t]{3}{*}{ Experimental } & \multirow[t]{3}{*}{ Aortic clamping and cardioplegic arrest } & \multirow{3}{*}{$\begin{array}{l}\mathrm{Pa}_{\mathrm{a}} \mathrm{O}_{2}=40-50 \mathrm{mmHg} \text { gradually } \\
\text { increased towards normoxemia over } \\
\text { a } 10 \text { minute period }\end{array}$} & $\uparrow$ hemodynamic profile \\
\hline & & & & $\downarrow$ myocardial injury \\
\hline & & & & $\downarrow$ oxidative response \\
\hline Abdel-Rahman et al. [48] & Clinical & CPB for $C A B G$ & $\begin{array}{l}\mathrm{PaO}_{2}=50 \mathrm{mmHg} \text { with return to } \\
\text { normoxemia over a } 5 \text { minute period }\end{array}$ & $\downarrow$ oxidative response \\
\hline Fercakova et al. [49] & Experimental & Infrarenal aortic occlusion & Graded postischemic reoxygenation & $\uparrow$ neuroprotection \\
\hline Daxnerova et al. [50] & Experimental & Infrarenal aortic occlusion & Graded postischemic reoxygenation & $\uparrow$ neuroprotection \\
\hline Marsala et al. [51] & Experimental & Infrarenal aortic occlusion & Graded postischemic reoxygenation & $\begin{array}{l}\downarrow \text { neuropathological } \\
\text { damage }\end{array}$ \\
\hline Orendacova et al. [52] & Experimental & Infrarenal aortic occlusion & $\begin{array}{l}\mathrm{Pa}_{\mathrm{a}} \mathrm{O}_{2}=48 \mathrm{mmHg} \text { with gradual return } \\
\text { to normoxemia over a } 15 \text { minute } \\
\text { period }\end{array}$ & $\uparrow$ neuroprotection \\
\hline Lukacova et al. [53] & Experimental & Infrarenal aortic occlusion & $\begin{array}{l}\mathrm{P}_{\mathrm{a}} \mathrm{O}_{2}=48 \pm 12 \mathrm{mmHg} \text { with gradual } \\
\text { return to normoxemia over a } \\
30 \text { minute period }\end{array}$ & $\uparrow$ neuroprotection \\
\hline Lehmann et al. [54] & Experimental & Supraceliac aortic clamp & $\begin{array}{l}\mathrm{PaO}_{2}=25-35 \mathrm{mmHg} \text { for } 30 \text { minutes } \\
\text { with gradual return to normoxemia } \\
\text { over a } 90 \text { minute period }\end{array}$ & $\downarrow$ hemodynamic profile \\
\hline \multirow[t]{3}{*}{ Douzinas et al. [55] } & \multirow[t]{3}{*}{ Experimental } & \multirow[t]{3}{*}{ Hemorrhagic shock - exsanguination } & \multirow{3}{*}{$\begin{array}{l}\mathrm{FiO}_{2}=0.12 \text { with gradual increase to } \\
\mathrm{FiO}_{2}=0.21 \text { over a } 40 \text { minute period }\end{array}$} & $\uparrow$ hemodynamic profile \\
\hline & & & & $\downarrow$ oxidative response \\
\hline & & & & $\downarrow$ inflammatory response \\
\hline \multirow[t]{3}{*}{ Douzinas et al. [3] } & \multirow[t]{3}{*}{ Experimental } & \multirow[t]{3}{*}{ Hemorrhagic shock - exsanguination } & \multirow{3}{*}{$\begin{array}{l}\mathrm{FiO}_{2}=0.08-0.10 \text { with gradual } \\
\text { increase to } \mathrm{FiO}_{2}=0.21 \text { over a } \\
60 \text { minute period }\end{array}$} & $\uparrow$ hemodynamic profile \\
\hline & & & & $\downarrow$ oxidative response \\
\hline & & & & \inflammatory response \\
\hline \multirow[t]{2}{*}{ Douzinas et al. [56] } & \multirow[t]{2}{*}{ Experimental } & \multirow[t]{2}{*}{ Hemorrhagic shock - exsanguination } & \multirow{2}{*}{$\begin{array}{l}\mathrm{FiO}_{2}=0.08-0.10 \text { with gradual } \\
\text { increase to } \mathrm{FiO}_{2}=0.21 \text { over a } \\
60 \text { minute period }\end{array}$} & $\downarrow$ oxidative response \\
\hline & & & & $\downarrow$ inflammatory response \\
\hline Douzinas et al. [57] & Experimental & Hemorrhagic shock - exsanguination & $\begin{array}{l}\mathrm{FiO}_{2}=0.08-0.10 \text { with gradual } \\
\text { increase to } \mathrm{FiO}_{2}=0.21 \text { over a } \\
60 \text { minute period }\end{array}$ & $\uparrow$ vascular homeostasis \\
\hline \multirow[t]{2}{*}{ Douzinas et al. [58] } & \multirow[t]{2}{*}{ Experimental } & Hemorrhagic shock - exsanguination & $\mathrm{FiO}_{2}=0.08-0.10$ with gradual & $\downarrow$ oxidative response \\
\hline & & & $\begin{array}{l}\text { increase to } \mathrm{FiO}_{2}=0.21 \text { over a } \\
60 \text { minute period }\end{array}$ & \lung injury \\
\hline
\end{tabular}


Table 1 Summary of hypoxemic reperfusion studies (Continued)

\begin{tabular}{|c|c|c|c|c|}
\hline Douzinas et al. [59] & Experimental & Hemorrhagic shock - exsanguination & $\begin{array}{l}\mathrm{FiO}_{2}=0.08-0.10 \text { with gradual } \\
\text { increase to } \mathrm{FiO}_{2}=0.21 \text { over a } \\
60 \text { minute period }\end{array}$ & $\begin{array}{l}\downarrow \text { oxidative response } \\
\downarrow \text { inflammatory response } \\
\downarrow \text { lung injury }\end{array}$ \\
\hline Douzinas et al. [60] & Experimental & Hemorrhagic shock - exsanguination & $\begin{array}{l}\mathrm{FiO}_{2}=0.08-0.10 \text { with gradual } \\
\text { increase to } \mathrm{FiO}_{2}=0.21 \text { over a } \\
60 \text { minute period }\end{array}$ & $\begin{array}{l}\downarrow \text { oxidative response } \\
\downarrow \text { inflammatory response } \\
\downarrow \text { liver injury }\end{array}$ \\
\hline Luo et al. [61] & Experimental & Hemorrhagic shock - exsanguination & $\begin{array}{l}\mathrm{FiO}_{2}=0.11 \text { with gradual increase to } \\
\mathrm{FiO}_{2}=0.21 \text { over a } 60 \text { minute period }\end{array}$ & $\begin{array}{l}\downarrow \text { hemodynamic profile } \\
\text { —oxidative response } \\
\text { —inflammatory response }\end{array}$ \\
\hline
\end{tabular}

Table summarizes the data of the available studies of hypoxemic reperfusion presenting the setting, the model of ischemia - reperfusion injury studied, the reperfusion protocol and the main outcomes

$\mathrm{P}_{a} \mathrm{O}_{2}$ partial arterial oxygen pressure, $\mathrm{SMA}$ superior mesenteric artery, $\mathrm{FiO}_{2}$ fraction of inspired oxygen, $M A P$ mean arterial pressure, $C P B$ cardio-pulmonary bypass, $C A B G$ coronary artery bypass grafting

$\left(\mathrm{P}_{\mathrm{a}} \mathrm{O}_{2}=37.5 \mathrm{mmHg}\right)$ with gradual return to normoxemia $\left(\mathrm{P}_{\mathrm{a}} \mathrm{O}_{2}=82 \mathrm{mmHg}\right)$ exhibited increased cerebral protein synthesis. The favorable effect of hypoxemic reperfusion has also been tested in a porcine experimental model of global cerebral ischemia [44, 45], where hypoxemic reperfusion was found to result in improved neurological outcome as evidenced by the superior Overall Performance Category (OPC) score [44], decreased brain histopathologic damage [45] and reduced lipid peroxidation [44].

There has, however, been one study in which hypoxemic reperfusion was found to exacerbate neurological injury [46]. In a porcine model designed to resemble the clinical scenario of infants undergoing deep hypothermic circulatory arrest with diminished cerebral blood flow as employed during surgical intervention for complex congenital heart lesions, investigators applied maintained hypoxemic arterial oxygen tensions $\left(\mathrm{P}_{\mathrm{a}} \mathrm{O}_{2}, 40-50 \mathrm{mmHg}\right)$ throughout the reperfusion period without return to normoxemia [46]. While this was found to lead to worse outcomes, this method cannot be compared with other studies in which the reperfusion took place under hypoxemic conditions with gradual return to normoxemia.

\section{Myocardial reperfusion injury}

Myocardial reperfusion injury represents a devastating entity encountered in the clinical setting as a result of various conditions including percutaneous coronary intervention after acute myocardial infarction and cardiac surgery. The promising results of hypoxemic reperfusion have led to testing of this strategy in the setting of myocardial reperfusion injury, both in experimental and clinical studies.

Abdel - Rahman et al. used a porcine experimental model of cardiopulmonary bypass with aortic clamping and cardioplegic arrest to test the efficacy of the so-called gradual reoxygenation in the attenuation of myocardial reperfusion injury [47]. The results of their study indicate that applying hypoxemia at the onset of the reperfusion period with gradual return to normoxemia resulted in significantly less impairment of myocardial function, decreased myocardial injury and reduced oxidative damage.

The same group designed and conducted a prospective study, using nineteen consecutive patients who underwent cardiac surgery with cardiopulmonary bypass for scheduled coronary artery bypass grafting as the study's population [48]. Graded reoxygenation at the beginning of the reperfusion period led to a decrease in myocardial oxidative injury as signified by the lower MDA blood levels.

\section{Generalized ischemia - reperfusion injury}

Graded post-ischemic reoxygenation has also been the topic of investigation by Maršala and his group in the setting of aortic clamping induced ischemia. Using a rabbit experimental model, they found that gradual reoxygenation during reperfusion after infrarenal aortic occlusion, resulted in the preservation of the cytoplasmic and nuclear structures of the lumbosacral dorsal root ganglia neurons $[49,50]$. In a similar model of aortic clamping-induced spinal cord ischemia, they showed that the application of gradual reoxygenation reduced neuropathological damage [51], decreased blood - brain barrier permeability [52] and attenuated neuronal argyrophilia and reperfusion injury - induced alterations in neuronal organelles [53].

However, one study by Lehmann et al. using a porcine model of complete lower torso ischemia, found that hypoxemic reperfusion resulted in a deteriorated hemodynamic profile, increased lactic acidosis and higher inotropic agents requirements compared to normoxemic reperfusion [54]. A possible explanation for these findings which are discrepant from that of other studies is that in this study, there was a long aortic cross-clamp period, perhaps resulting in greater injury severity and ischemic insult.

\section{Hemorrhagic shock - resuscitation}

Hemorrhagic shock and resuscitation represents a model of whole body $I / R$ injury. In a pilot study, using a rat 
model of controlled hemorrhagic shock, hypoxemic resuscitation resulted in superior hemodynamic stabilization and less oxidative and inflammatory responses as evidenced by the decreased MDA and tumor necrosis factor alpha (TNF-a) serum levels [55]. Similar results were shown in a rabbit experimental model. Application of hypoxemic resuscitation was associated with more efficient blood pressure restoration as well as attenuation of the oxidative insult exerted by normoxemic resuscitation [3]. This was shown by the decreased production of ROS as assessed by flow cytometry, reduced MDA and higher ratio of reduced to total glutathione levels. Moreover, hypoxemic resuscitation resulted in attenuation of the inflammatory response as evidenced by the significantly lower serum levels of TNF-a, IL-1b and IL-6. These effects could be attributed to the lower stimulation of p38 mitogen activated protein kinase (MAPK) - mediated production of inflammatory cytokines by monocytes [56]. Additionally, using this combined in vivo and in vitro model, it was shown that the serum of normoxemically resuscitated animals could prime the otherwise inert U937 monocyte like cells for the production of inflammatory cytokines. This effect was abolished when the cells were incubated with the serum drawn from animals that were resuscitated under hypoxemic conditions, highlighting a favorable systemic effect [56]. The beneficial role of this strategy in the attenuation of the systemic inflammatory response is also supported by the resulting lower serum levels of angiopoietin-2, a key player in vascular homeostasis and inflammation [57]. Systemic inflammatory response and tissue hypoperfusion following ischemia and dysregulated vascular endothelial function are the major contributors of MOF. Taken together, these results could support the hypothesis that hypoxemic reperfusion confers protection against MOF through attenuation of the inflammatory response and preservation of vascular homeostasis. Hypoxemic reperfusion has also been found to protect from lung injury and pulmonary dysfunction, which constitute a significant problem encountered after resuscitation from hemorrhagic shock [58, 59]. The favorable effects of gradual reintroduction of oxygen, include preservation of pulmonary capillary endothelial angiotensin converting enzyme activity, lower lung tissue myeloperoxidase (MPO) activity, lower lung injury histopathological score and lower MDA and intracellular adhesion molecule (ICAM) -1 and vascular cell adhesion molecule (VCAM) -1 expression levels. In another set of experiments, hypoxemic resuscitation was associated with decreased bronchoalveolar lavage (BAL) ROS levels as measured by flow cytometry as well as reduced inflammatory cytokine levels including TNF-a, IL$1 \mathrm{~b}$ and IL-6. In addition, the nitrotyrosine score, as a marker of nitrosative stress mediated injury, was higher in the normoxemic resuscitation group of animals. Moreover, another favorable effect of hypoxemic resuscitation from hemorrhagic shock is the prevention of post-ischemic liver injury through the attenuation of nitrosative and oxidative stresses [60]. These effects were evidenced by the lower serum ROS and cytokines (TNF-a, IL-1b and IL-6) levels, the lower hepatic MDA levels and the decreased hepatic MPO and endothelial nitric oxide synthase (eNOS) and inducible nitric oxide synthase (iNOS) expression. These results, regarding the lower degree of injury of isolated organs (i.e. lung and liver) also highlight the potential beneficial role of hypoxemic reperfusion in the prevention of MOF. More recently, Luo et al. [61] compared the effects of normoxic, hyperoxic, hypoxemic and gradual resuscitation from hypoxia to hyperoxia (gradually increased oxygen administration - GIOA technique) in a rat experimental model. The authors showed that hypoxemic resuscitation resulted in worse hemodynamic profile as evidenced by the significantly lower pulse pressure as well as lower liver tissue oxygen partial pressure compared to GIOA resuscitation. The hypoxemic mode of reperfusion showed significantly lower liver injury, oxidative and inflammatory responses, only compared to hyperoxic resuscitation, while no statistically significant differences were demonstrated between GIOA and hypoxemic groups. However, the discordance between these results and previously published data [3] could be attributed to the relatively shorter follow up period in Luo's study [61]. Longer follow up period in that study, could eventually unmask detrimental effects of the applied hyperoxemia in the context of GIOA, in contrast to normoxemia.

\section{Conclusions}

The pivotal role of oxidative stress mediated injury after ischemia and reperfusion has been well established. Over the last decades, medical research has focused on the elucidation of the underlying pathophysiologic mechanisms in an attempt to develop strategies to attenuate this $I / R$ injury. Hypoxemic reperfusion has been proposed as a technique aimed at the elimination of the oxidative burst that leads to the downstream cascade of free radicals and inflammation leading to multiple organ injury. This method has shown promise in various cases of $I / R$ injury both in the experimental and clinical setting. However, further research both to clarify its underlying basic mechanisms and to assess its efficacy in the clinical setting is warranted.

\footnotetext{
Abbreviation

ATP: adenosine triphosphate; BAL: bronchoalveolar lavage; $\mathrm{C}_{a} \mathrm{O}_{2}$ : arterial oxygen content; $\mathrm{CO}$ : cardiac output; $\mathrm{DO}_{2}$ : oxygen delivery; eNOS: endothelial nitric oxide synthase; $\mathrm{FiO}_{2}$ : fraction of inspired oxygen; $\mathrm{GlOA}$ : gradually increased oxygen administration; Hb: hemoglobin; I/R: ischemia - reperfusion; ICAM: intracellular adhesion molecule; IL: interleukin; iNOS: inducible nitric oxide synthase; MAPK: mitogen activated protein kinase; MDA: malondialdehyde; MOF: multiple organ failure; MPO: myeloperoxidase; OPC: overall performance score; $\mathrm{P}_{\mathrm{a}} \mathrm{O}_{2}$ : partial arterial oxygen pressure; $\mathrm{ROS}$ : reactive oxygen species; $\mathrm{S}_{\mathrm{a}} \mathrm{O}_{2}$ : arterial oxygen saturation; $\mathrm{S} \quad \mathrm{O}_{2}$ : mixed oxygen venous saturation; TNF: tumor necrosis factor; VCAM: vascular cell adhesion molecule.
} 


\section{Competing interests}

The authors declare that they have no competing interests.

\section{Authors' contributions}

MKT: Carried out the search of the literature, analysis of the results and drafted the manuscript. EED: Conceived the idea and participated in the analysis of the results and drafted the manuscript. Both authors read and approved the final manuscript.

\section{Acknowledgements}

The authors are grateful to Dr. Anees B. Chagpar, MD, MSc, MPH, MA, MBA, FRCS(C), FACS, Associate Professor of Surgery, Yale University School of Medicine for editorial assistance and language review of the manuscript.

\section{Author details}

2nd Department of Surgery, National and Kapodistrian University of Athens, Medical School, Aretaieion University Hospital, 76 Vas. Sofias Ave, 11528 Athens, Greece. ${ }^{2} 3$ rd Department of Critical Care Medicine, National and Kapodistrian University of Athens, Medical School, Evgenideio Hospital, 20 Papadiamantopoulou St., 11528 Athens, Greece.

Received: 9 October 2015 Accepted: 11 January 2016

Published online: 19 January 2016

\section{References}

1. McCord JM. Oxygen-derived free radicals in postischemic tissue injury N Engl J Med. 1985;312(3):159-63.

2. Yellon DM, Hausenloy DJ. Myocardial reperfusion injury. N Engl J Med. 2007;357(11):1121-35.

3. Douzinas EE, Livaditi $\mathrm{O}$, Andrianakis I, Prigouris P, Paneris P, Villiotou V, et al. The effect of hypoxemic resuscitation from hemorrhagic shock on blood pressure restoration and on oxidative and inflammatory responses. Intensive Care Med. 2008;34(6):1133-41.

4. Ambler SK, Hodges YK, Jones GM, Long CS, Horwitz LD. Prolonged administration of a dithiol antioxidant protects against ventricular remodeling due to ischemia-reperfusion in mice. Am J Physiol Heart Circ Physiol. 2008;295(3):H1303-10.

5. Dare AJ, Bolton EA, Pettigrew GJ, Bradley JA, Saeb-Parsy K, Murphy MP. Protection against renal ischemia-reperfusion injury in vivo by the mitochondria targeted antioxidant MitoQ. Redox Biology. 2015;5:163-8.

6. Song J, Park J, Oh Y, Lee JE. Glutathione suppresses cerebral infarct volume and cell death after ischemic injury: involvement of $\mathrm{FOXO} 3$ inactivation and Bcl2 expression. Oxidative Med Cell Longev. 2015;2015:426069.

7. Zhang Z, Yan J, Taheri S, Liu KJ, Shi H. Hypoxia-inducible factor 1 contributes to N-acetylcysteine's protection in stroke. Free Radic Biol Med. 2014;68:8-21.

8. Chen $\mathrm{CL}$, Zheng H, Xuan Y, Amat A, Chen L, Yu J, et al. The cardioprotective effect of hypoxic and ischemic preconditioning in dogs with myocardial ischemia-reperfusion injury using a double-bypass model. Life Sci. 2015;141:25-31.

9. Ji YY, Wang ZD, Wang SF, Wang BT, Yang ZA, Zhou XR, et al. Ischemic preconditioning ameliorates intestinal injury induced by ischemia-reperfusion in rats. World J Gastroenterol. 2015;21(26):8081-8.

10. Lu MJ, Chen YS, Huang HS, Ma MC. Hypoxic preconditioning protects rat hearts against ischemia-reperfusion injury via the arachidonate12-lipoxygenase/ transient receptor potential vanilloid 1 pathway. Basic Res Cardiol. 2014;109(4):414

11. Chouker A, Ohta A, Martignoni A, Lukashev D, Zacharia LC, Jackson EK, et al. In vivo hypoxic preconditioning protects from warm liver ischemia-reperfusion injury through the adenosine A2B receptor. Transplantation. 2012;94(9):894-902.

12. Qiao S, Mao X, Wang Y, Lei S, Liu Y, Wang T et al. Remifentanil Preconditioning Reduces Postischemic Myocardial Infarction and Improves Left Ventricular Performance via Activation of the Janus Activated Kinase-2/ Signal Transducers and Activators of Transcription-3 Signal Pathway and Subsequent Inhibition of Glycogen Synthase Kinase-3beta in Rats. Critical Care Med. 2015. doi:10.1097/CCM.0000000000001350.

13. Savvanis S, Nastos C, Tasoulis MK, Papoutsidakis N, Demonakou M, Karmaniolou I, et al. Sildenafil attenuates hepatocellular injury after liver ischemia reperfusion in rats: a preliminary study. Oxidative Med Cell Longev. 2014:2014:161942.
14. Mahfoudh-Boussaid A, Zaouali MA, Hadj-Ayed K, Miled AH, Saidane-Mosbahi D. Rosello-Catafau J, et al. Ischemic preconditioning reduces endoplasmic reticulum stress and upregulates hypoxia inducible factor-1alpha in ischemic kidney: the role of nitric oxide. J Biomed Sci. 2012;19:7.

15. Hu X, Yang Z, Yang M, Qian J, Cahoon J, Xu J, et al. Remote ischemic preconditioning mitigates myocardial and neurological dysfunction via K(ATP) channel activation in a rat model of hemorrhagic shock. Shock. 2014;42(3):228-33.

16. Cai Z, Luo W, Zhan H, Semenza GL. Hypoxia-inducible factor 1 is required for remote ischemic preconditioning of the heart. Proc Natl Acad Sci U S A. 2013;110(43):17462-7.

17. Abu-Amara M, Yang SY, Quaglia A, Rowley P, Tapuria N, Fuller B, et al. The hepatic soluble guanylyl cyclase-cyclic guanosine monophosphate pathway mediates the protection of remote ischemic preconditioning on the microcirculation in liver ischemia-reperfusion injury. Transplantation 2012;93(9):880-6.

18. Frohlich GM, Meier P, White SK, Yellon DM, Hausenloy DJ. Myocardial reperfusion injury: looking beyond primary PCI. Eur Heart J. 2013;34(23):1714-22.

19. Abu-Amara M, Gurusamy K, Hori S, Glantzounis G, Fuller B, Davidson BR. Systematic review of randomized controlled trials of pharmacological interventions to reduce ischaemia-reperfusion injury in elective liver resection with vascular occlusion. HPB (Oxford). 2010;12(1):4-14.

20. O'Neill S, Leuschner S, McNally SJ, Garden OJ, Wigmore SJ, Harrison EM. Meta-analysis of ischaemic preconditioning for liver resections. Br J Surg. 2013;100(13):1689-700.

21. Nicholson ML, Pattenden CJ, Barlow AD, Hunter JP, Lee G, Hosgood SA. A Double Blind Randomized Clinical Trial of Remote Ischemic Conditioning in Live Donor Renal Transplantation. Medicine. 2015;94(31):e1316.

22. Meybohm P, Bein B, Brosteanu O, Cremer J, Gruenewald M, Stoppe C, et al. A Multicenter Trial of Remote Ischemic Preconditioning for Heart Surgery. N Engl J Med. 2015;373(15):1397-407.

23. Hausenloy DJ, Candilio L, Evans R, Ariti C, Jenkins DP, Kolvekar S, et al. Remote Ischemic Preconditioning and Outcomes of Cardiac Surgery. N Engl Med. 2015:373(15):1408-17.

24. Tasoulis MK, Livaditi O, Stamatakos M, Stefanaki C, Paneris $\mathrm{P}$, Prigouris $\mathrm{P}$, et al. High concentrations of reactive oxygen species in the BAL fluid are correlated with lung injury in rabbits after hemorrhagic shock and resuscitation. Tohoku J Exp Med. 2009:219(3):193-9.

25. Liu KX, Li YS, Huang WQ, Chen SQ, Wang ZX, Liu JX, et al. Immediate postconditioning during reperfusion attenuates intestinal injury. Intensive Care Med. 2009;35(5):933-42

26. Touboul C, Angoulvant D, Mewton N, Ivanes F, Muntean D, Prunier F, et al. Ischaemic postconditioning reduces infarct size: systematic review and meta-analysis of randomized controlled trials. Arch Cardiovasc Dis. 2015;108(1):39-49.

27. Khan AR, Binabdulhak AA, Alastal Y, Khan S, Faricy-Beredo BM, Luni FK, et al. Cardioprotective role of ischemic postconditioning in acute myocardial infarction: a systematic review and meta-analysis. Am Heart J. 2014:168(4):512-21. e4.

28. van den Akker EK, Manintveld OC, Hesselink DA, de Bruin RW, ljzermans JN, Dor FJ. Protection against renal ischemia-reperfusion injury by ischemic postconditioning. Transplantation. 2013;95(11):1299-305.

29. Mahfoudh-Boussaid A, Zaouali MA, Hauet T, Hadj-Ayed K, Miled AH, Ghoul-Mazgar S, et al. Attenuation of endoplasmic reticulum stress and mitochondrial injury in kidney with ischemic postconditioning application and trimetazidine treatment. J Biomed Sci. 2012;19:71.

30. Guo JY, Yang T, Sun XG, Zhou NY, Li FS, Long D, et al. Ischemic postconditioning attenuates liver warm ischemia-reperfusion injury through Akt-eNOS-NO-HIF pathway. J Biomed Sci. 2011:18:79.

31. Kerendi F, Kin H, Halkos ME, Jiang R, Zatta AJ, Zhao ZQ, et al. Remote postconditioning. Brief renal ischemia and reperfusion applied before coronary artery reperfusion reduces myocardial infarct size via endogenous activation of adenosine receptors. Basic Res Cardiol. 2005:100(5):404-12

32. Xu J, Sun S, Lu X, Hu X, Yang M, Tang W. Remote ischemic pre- and postconditioning improve postresuscitation myocardial and cerebral function in a rat model of cardiac arrest and resuscitation. Crit Care Med. 2015:43(1):e12-8.

33. Wang T, Zhou YT, Chen XN, Zhu AX, Wu BH. Remote ischemic postconditioning protects against gastric mucosal lesions in rats. World J Gastroenterol. 2014;20(28):9519-27. 
34. Crimi G, Pica S, Raineri C, Bramucci E, De Ferrari GM, Klersy C, et al. Remote ischemic post-conditioning of the lower limb during primary percutaneous coronary intervention safely reduces enzymatic infarct size in anterior myocardial infarction: a randomized controlled trial. J Am Coll Cardiol Intv. 2013;6(10):1055-63.

35. Wang HC, Zhang HF, Guo WY, Su H, Zhang KR, Li QX, et al. Hypoxic postconditioning enhances the survival and inhibits apoptosis of cardiomyocytes following reoxygenation: role of peroxynitrite formation. Apoptosis. 2006;11(8):1453-60.

36. Sun HY, Wang NP, Kerendi F, Halkos M, Kin H, Guyton RA, et al. Hypoxic postconditioning reduces cardiomyocyte loss by inhibiting ROS generation and intracellular Ca2+ overload. Am J Physiol Heart Circ Physiol. 2005:288(4):H1900-8.

37. Naparus A, Ashrafpour H, Hofer SO, Zhong T, Huang N, Cahoon NJ, et al. Efficacy and mechanism of hypoxic postconditioning in salvage of ex vivo human rectus abdominis muscle from hypoxia/reoxygenation injury. Eur J Pharmacol. 2012;686(1-3):90-6.

38. Li Y, Guo Q, Liu X, Wang C, Song D. PUMA-mediated mitochondrial apoptotic disruption by hypoxic postconditioning. Apoptosis. 2015;20(8):1026-32

39. Younkin DP, Wagerle LC, Chance B, Maria J, Delivoria-Papadopoulos M. 31P-NMR studies of cerebral metabolic changes during graded hypoxia in newborn lambs. J Appl Physiol. 1987;62(4):1569-74.

40. Perry MA, Wadhwa SS. Gradual reintroduction of oxygen reduces reperfusion injury in cat stomach. Am J Physiol. 1988;254(3 Pt 1):G366-72.

41. Douzinas EE, Kollias S, Tiniakos D, Evangelou E, Papalois A, Rapidis AD, et al. Hypoxemic reperfusion after 120 mins of intestinal ischemia attenuates the histopathologic and inflammatory response. Crit Care Med. 2004;32(11):2279-83.

42. Douzinas EE, Pitaridis MT, Patsouris E, Kollias S, Boursinos V, Karmpaliotis DI, et al. Myocardial ischemia in intestinal postischemic shock: the effect of hypoxemic reperfusion. Crit Care Med. 2003;31(8):2183-9.

43. Burda J, Marsala M, Radonak J, Marsala J. Graded postischemic reoxygenation ameliorates inhibition of cerebral cortical protein synthesis in dogs. J Cereb Blood Flow Metab. 1991;11(6):1001-5.

44. Douzinas EE, Andrianakis I, Pitaridis MT, Karmpaliotis DJ, Kypriades EM, Betsou A, et al. The effect of hypoxemic reperfusion on cerebral protection after a severe global ischemic brain insult. Intensive Care Med. 2001;27(1):269-75.

45. Douzinas EE, Patsouris E, Kypriades EM, Makris DJ, Andrianakis I, Korkolopoulou P, et al. Hypoxaemic reperfusion ameliorates the histopathological changes in the pig brain after a severe global cerebral ischaemic insult. Intensive Care Med. 2001:27(5):905-10.

46. Hickey EJ, You X, Kaimaktchiev V, Ungerleider RM. Hypoxemic reperfusion exacerbates the neurological injury sustained during neonatal deep hypothermic circulatory arrest: a model of cyanotic surgical repair. Eur J Cardiothorac Surg. 2007;31(5):906-14.

47. Abdel-Rahman U, Risteski P, Tizi K, Kerscher S, Behjati S, Zwicker K, et al. Hypoxic reoxygenation during initial reperfusion attenuates cardiac dysfunction and limits ischemia-reperfusion injury after cardioplegic arrest in a porcine model. J Thorac Cardiovasc Surg. 2009;137(4):978-82.

48. Abdel-Rahman U, Aybek T, Moritz A, Kleine P, Matheis G. Graded reoxygenation limits lipid peroxidation during surgical reperfusion. Med Sci Monit. 2003;9(9):CR389-91.

49. Fercakova A, Marsala M, Marsala J. Influence of graded postischemic reoxygenation on reperfusion alterations in rabbit dorsal root ganglion neurons. J Hirnforsch. 1994;35(2):295-302.

50. Daxnerova Z, Marsala M, Marsala J. Graded postischemic reoxygenation attenuates ischemia-reperfusion-induced nuclear and nucleolar damage in lumbosacral dorsal root ganglia neurons. A light and electron microscopic study in rabbit. J Hirnforsch. 1995;36(3):379-91.

51. Marsala M, Danielisova V, Chavko M, Hornakova A, Marsala J. Improvement of energy state and basic modifications of neuropathological damage in rabbits as a result of graded postischemic spinal cord reoxygenation. Exp Neurol. 1989;105(1):93-103.

52. Orendacova J, Marsala M, Marsala J. The blood-brain barrier permeability in graded postischemic spinal cord reoxygenation in rabbits. Neurosci Lett. 1991;128(2):143-6

53. Lukacova N, Marsala M, Halat G, Marsala J. Neuroprotective effect of graded postischemic reoxygenation in spinal cord ischemia in the rabbit. Brain Res Bull. 1997;43(5):457-65.

54. Lehmann RK, Brounts LR, Lesperance KE, Eckert MJ, Lesperance RN, Beekley $A C$, et al. Hypoxemic versus normoxemic reperfusion in a large animal model of severe ischemia-reperfusion injury. J Surg Res. 2011;166(2):194-8.
55. Douzinas EE, Livaditi O, Xiarchos AG, Giamarellos-Bourboulis EJ, Villiotou V, Liappas IA, et al. The effect of hypoxemic resuscitation of hemorrhagic shock on hemodynamic stabilization and inflammatory response: a pilot study in a rat experimental model. J Trauma. 2006;61(4):918-23.

56. Douzinas EE, Livaditi O, Tasoulis MK, Pelekanou A, Giamarellos-Bourboulis EJ. Stimulation of monocytes is a pathway involved in systemic inflammatory response following haemorrhagic shock resuscitation: the effect of hypoxaemic resuscitation. Clin Exp Immunol. 2007;150(3):502-8.

57. Douzinas EE, Betrosian A, Livaditi O, Flevari K, Kanni T, Mouktaroudi M, et al. Hypoxemic resuscitation after hemorrhagic shock is accompanied by reduced serum levels of angiopoietin-2. Cytokine. 2009:47(2):82-4.

58. Douzinas EE, Orfanos SE, Livaditi O, Augustatou K, Villiotou V, Kavantzas N, et al. Hypoxemic resuscitation prevents pulmonary capillary endothelial dysfunction induced by normoxemic resuscitation from hemorrhagic shock. Crit Care Med. 2009;37(3):869-75.

59. Douzinas EE, Betrosian A, Giamarellos-Bourboulis EJ, Tasoulis MK, Prigouris $P$, Livaditi $\mathrm{O}$, et al. Hypoxemic resuscitation from hemorrhagic shock prevents lung injury and attenuates oxidative response and IL-8 overexpression. Free Radic Biol Med. 2011;50(2):245-53.

60. Douzinas EE, Livaditi O, Tasoulis MK, Prigouris P, Bakos D, Goutas N, et al. Nitrosative and oxidative stresses contribute to post-ischemic liver injury following severe hemorrhagic shock: the role of hypoxemic resuscitation. PLoS One. 2012;7(3):e32968.

61. Luo X, Yin Y, You G, Chen G, Wang Y, Zhao J, et al. Gradually Increased Oxygen Administration Improved Oxygenation and Mitigated Oxidative Stress after Resuscitation from Severe Hemorrhagic Shock. Anesthesiology. 2015;123(5):1122-32

\section{Submit your next manuscript to BioMed Central and we will help you at every step:}

- We accept pre-submission inquiries

- Our selector tool helps you to find the most relevant journal

- We provide round the clock customer support

- Convenient online submission

- Thorough peer review

- Inclusion in PubMed and all major indexing services

- Maximum visibility for your research

Submit your manuscript at www.biomedcentral.com/submit
Biomed Central 